\title{
Global Epidemiology of End-Stage Kidney Disease and Disparities in Kidney Replacement Therapy
}

\author{
John S. Thurlowa, ${ }^{a}$ Megha Joshi ${ }^{a, b}$ Guofen Yan ${ }^{c}$ Keith C. Norris ${ }^{d}$ \\ Lawrence Y. Agodoa ${ }^{\mathrm{e}}$ Christina M. Yuan ${ }^{\mathrm{a}, \mathrm{b}}$ Robert Nee ${ }^{\mathrm{a}, \mathrm{b}}$ \\ ${ }^{a}$ Nephrology Service, Walter Reed National Military Medical Center, Bethesda, MD, USA; bDepartment of Medicine, \\ Uniformed Services University, Bethesda, MD, USA; 'Department of Public Health Sciences, University of Virginia

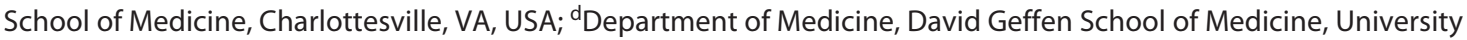 \\ of California at Los Angeles, Los Angeles, CA, USA; ${ }^{\circ}$ Office of the Director, National Institute of Diabetes and \\ Digestive and Kidney Diseases, National Institutes of Health, Bethesda, MD, USA
}

\section{Keywords}

Global epidemiology · End-stage kidney disease · Kidney replacement therapy · Dialysis · Hemodialysis · Peritoneal dialysis · Kidney transplant · Disparities · Income · Mortality

\begin{abstract}
Background: The global epidemiology of end-stage kidney disease (ESKD) reflects each nation's unique genetic, environmental, lifestyle, and sociodemographic characteristics. The response to ESKD, particularly regarding kidney replacement therapy (KRT), depends on local disease burden, culture, and socioeconomics. Here, we explore geographic variation and global trends in ESKD incidence and prevalence and examine variations in KRT modality, practice patterns, and mortality. We conclude with a discussion on disparities in access to KRT and strategies to reduce ESKD global burden and to improve access to treatment in low- and middle-income countries (LMICs). Summary: From 2003 to 2016, incidence rates of treated ESKD were relatively stable in many higher income countries but rose substantially predominantly in East and Southeast Asia. The prevalence of treated ESKD has increased worldwide, likely due to improving ESKD
\end{abstract}

survival, population demographic shifts, higher prevalence of ESKD risk factors, and increasing KRT access in countries with growing economies. Unadjusted 5-year survival of ESKD patients on KRT was $41 \%$ in the USA, $48 \%$ in Europe, and $60 \%$ in Japan. Dialysis is the predominant KRT in most countries, with hemodialysis being the most common modality. Variations in dialysis practice patterns account for some of the differences in survival outcomes globally. Worldwide, there is a greater prevalence of KRT at higher income levels, and the number of people who die prematurely because of lack of KRT access is estimated at up to 3 times higher than the number who receive treatment. Key Messages: Many people worldwide in need of KRT as a life-sustaining treatment do not receive it, mostly in LMICs where health care resources are severely limited. This large treatment gap demands a focus on population-based prevention strategies and development of affordable and cost-effective KRT. Achieving global equity in KRT access will require concerted efforts in advocating effective public policy, health care de-

This is a work of the US Government and is not subject to copyright protection in the USA. Foreign copyrights may apply.

Published by S. Karger AG, Basel. karger@karger.com

www.karger.com/ajn

Karger
(C) 2021 S. Karger AG, Basel
Robert Nee

Nephrology Service, Walter Reed National Military Medical Center

8901 Wisconsin Avenue

Bethesda, MD 20889 (USA)

robert.nee.civ@mail.mil 
livery, workforce capacity, education, research, and support from the government, private sector, nongovernmental, and professional organizations.

(c) 2021 S. Karger AG, Basel

\section{Introduction}

End-stage kidney disease (ESKD) is a rapidly increasing global health and health care burden. The inability to care for many patients at risk for and in need of treatment for ESKD disproportionately impacts low- and middleincome countries (LMICs). Defining global ESKD epidemiology is an essential first step in evaluating international response. In this review, we explore geographic variation and global trends in treated ESKD incidence and prevalence based on national reports and registry data. The United States Renal Data System (USRDS) compiles and publishes international survey data annually from 79 countries and regions [1]. Data include only those ESKD patients who are on dialysis or have received a kidney transplant (i.e., treated ESKD). This underestimates true incidence and prevalence, due to unrecognized ESKD and limited access to kidney replacement therapy (KRT) in many countries. Notably, national ESKD data are not available in many LMICs in Africa and 2 populous developing nations - China and India.

The international response to ESKD is complex, influenced by local disease burden, culture, and socioeconomics. An estimated 2.6 million people received KRT worldwide in 2010 [2]. However, 4.9-9.7 million people were estimated to require KRT in 2010 , suggesting that $\geq 2.3$ million people might have died because of lack of access to this life-sustaining therapy. Thus, only half or less of all people needing KRT worldwide had access to it. Further, the proportion of people with ESKD not receiving KRT was much higher in low (96\%) and lower-middle (90\%) income countries than in upper-middle (70\%) and high (40\%) income countries [3]. The largest treatment gaps occurred in low-income countries, particularly in Asia and Africa. In Asia, $17-34 \%$ of people needing KRT received treatment. In Africa, 9-16\% of people needing KRT received treatment [2]. By 2030, worldwide use of KRT is projected to more than double to 5.4 million people, with the most growth in Asia [2].

Given the anticipated global growth in ESKD, it is imperative to understand how international outcomes differ according to KRT management strategies. Therefore, we examine international variations in KRT modality and practice patterns, mortality, disparities in access to KRT at the country level, and when data are available disparities at the individual level within a country. We conclude with a discussion of strategies to reduce global ESKD burden and inequities in KRT access.

\section{Geographic Variation and Global Trends in the Incidence of Treated ESKD}

Based on the International Society of Nephrology's (ISN) 2019 Global Kidney Health Atlas (GKHA) cross-sectional survey of 160 participating countries, information on treated ESKD incidence was available in 79 countries, and the average number of new ESKD diagnoses worldwide was 144 individuals per million general population (pmp) [3]. In 2016, USRDS-reported incidence rates of treated ESKD varied greatly across countries (see online suppl. Table 1; see www.karger.com/doi/10.1159/000514550 for all online suppl. material) [1]. Taiwan, the USA, the Jalisco region of Mexico, and Thailand reported the highest incidences of treated ESKD (493, 378, 355, and 346 pmp/year, respectively). The lowest treated ESKD incidences, ranging from 22 to $85 \mathrm{pmp}$ /year, were reported by South Africa, Ukraine, Belarus, Bangladesh, Russia, Jordan, Peru, Colombia, Iran, Albania, and Estonia.

Among high-income countries (HICs), ESKD incidence is the lowest in Nordic countries, other European countries, Australia, and New Zealand [4]. These have nearly universal health care systems, including KRT access, so the lower rates could be due to relatively low incidence or delayed chronic kidney disease (CKD) progression. Other potential explanations include dialysis commencement at lower glomerular filtration rates, greater adoption of conservative care management, and health care reform strategies focusing on cost containment [5]. ESKD incidence is much higher in the USA and high-income East and Southeast Asian countries, likely reflecting greater CKD burden and associated risk factors such as diabetes, hypertension, obesity, and glomerular diseases (e.g., IgA nephropathy in Asia), greater health care spending, and improving survival among those with CKD. Government policies have also improved KRT access. In Taiwan, the National Health Insurance program provides full coverage for dialysis therapy without copayment [6]. In Thailand, implementation of a "PD-first" universal coverage policy in which all eligible patients are offered peritoneal dialysis (PD) with the more costly hemodialysis (HD) restricted to patients with a clinical indication or private insurance coverage has led to expansion of ESKD care [7]. 
Among HICs, the incidence rate trends for treated ESKD are relatively stable, either declining modestly or increasing slightly by $\sim 2$ pmp/year from 2003 to 2016, including Nordic and other European countries, Australia, New Zealand, Japan, and the USA [1]. This may suggest that treatment of diabetes and hypertension has improved over this 14-year period, reducing CKD onset and slowing its progression [4]. In contrast, treated ESKD incidence rates have risen substantially from 2003 to 2016 in East and Southeast Asian countries, including Thailand, Malaysia, the Republic of Korea, Singapore, the Philippines, and Taiwan [1]. This may reflect an aging population; an increased burden of diabetes, hypertension, and obesity; and economic development that improved KRT access [8].

\section{Incidence Rates of ESKD in the USA}

Since 2011, the crude ESKD incidence rate in the USA has risen; however, the age-sex-race standardized incidence rate appears to have plateaued [1]. The standardized ESKD incidence rate rose sharply in the 1980s and 1990s, leveled off in early 2006, and has declined slightly since. This downward trend may suggest improved prevention or delay of ESKD onset. However, projected demographic, clinical, and lifestyle characteristics of the US population may reverse the current downward trend. A simulation model incorporating trends in population demographics, obesity, diabetes, and hypertension projected an 11-18\% increase in crude incidence rate from 2015 to 2030 [9]. Combined with ESKD mortality declines, this could increase prevalence by 29-68\%. The projected rise in ESKD incidence and prevalence in the USA is due to an aging population, rising diabetes and hypertension burden, decreasing ESKD mortality due to improved care, and an increasing proportion of African-Americans in the US population.

African-Americans and other racial/ethnic minority and socially disadvantaged groups account for a disproportionate share of the ESKD population in the USA, largely reflecting inequities in health care access and delivery and associated increased disease burden and poor clinical outcomes [10]. Mechanisms underlying these racial and ethnic disparities represent a complex interplay of genetic, biological, environmental, sociocultural, socioeconomic, and health care system level factors [11]. According to the World Health Organization Commission on Social Determinants of Health, the social gradient in health within and between countries is caused by unequal distribution of power, income, goods, and services, mainly due to unjust social and economic policies [12]. Social determinants of health include health services (e.g., access to and quality of care and insurance status), social environment (e.g., discrimination, income, and education level), physical environment (e.g., place of residence, living conditions, and transportation), health literacy, and legislative policies $[13,14]$. The maldistribution of these factors is associated with increased development and progression of CKD and CKD risk factors, lower access to health care, and worse morbidity and mortality in the CKD and ESKD population [15].

\section{Geographic Variation and Global Trends in the Prevalence of Treated ESKD}

In 2016, 2,455,004 patients were treated for ESKD across all countries reporting data to the USRDS [1]. Based on the ISN's 2019 GKHA survey, information on treated ESKD prevalence was available in 91 countries, and the average number of people receiving treatment for ESKD globally was $759 \mathrm{pmp}$ [3]. The USA has the most, with 709,501 treated patients (29\%), followed by Japan $(328,000$; $13 \%)$ and Brazil (180,000; 7\%). Treated ESKD prevalence varied nearly 30 -fold across represented countries (online suppl. Table 1) $[1,16]$. Taiwan reported the highest treated ESKD prevalence (3,392 pmp), followed by Japan $(2,599 \mathrm{pmp})$ and the USA (2,196 pmp). The lowest prevalences, 117-540 pmp, were reported by Bangladesh, South Africa, Ukraine, Belarus, Iraq, Russia, Indonesia, Guatemala, Albania, Peru, Latvia, Serbia, and Bulgaria.

Although ESKD incidence has stabilized or decreased in many countries, ESKD prevalence has increased by a median 43\% from 2003 to 2016 [1]. Countries with the highest percentage rise in ESKD prevalence were Taiwan, the USA, the Republic of Korea, Thailand, the Jalisco region of Mexico, Chile, Malaysia, Turkey, Brazil, the Philippines, and Russia [1]. Rising ESKD prevalence worldwide may be due to improved survival; aging of the world population; increases in diabetes, hypertension, and obesity, associated with urbanization and changes in diet and physical activity; and increasing KRT access in countries with growing economies $[2,4]$.

\section{ESKD in China, India, and Africa}

In China, the most populous country in the world (1.4 billion people), there are ongoing efforts to establish a national kidney registry [17]. The China Kidney Disease 
Network (CK-NET) was initiated in 2014, with its mission to integrate various sources of data in China to better inform health care policy, strengthen academic research, and promote effective management in patients with kidney disease. Using 2 large nationwide claims databases (China Health Insurance Research and Commercial Health Insurance), the estimated age-adjusted incidence rate of dialysis was $122 \mathrm{pmp}$ /year. Also, in 2015, the estimated prevalence of HD and PD was 402 and $40 \mathrm{pmp}$, respectively (553,000 $\mathrm{HD}$ and 55,000 $\mathrm{PD}$ patients).

India, the 2nd most populous country in the world, also lacks a national registry for ESKD [18]. Most estimates are extrapolated from subregions of India or hospital-based registries. A population-based study from a large urban cohort estimated an age-adjusted ESKD incidence of $232 \mathrm{pmp}$ [19]. In 2010, 52,273 adult CKD patients were analyzed, and $61 \%$ of those with ESKD were not on any form of KRT, $32 \%$ were on $\mathrm{HD}, 5 \%$ on PD, and $2 \%$ were evaluated for transplant [20].

In Africa, the vast majority of cases of ESKD likely remain undiagnosed and untreated, leading to almost certain mortality [21]. Limited aggregate data exist to accurately characterize ESKD rates, which are likely quite high, and steps to establish a continent-wide registry are ongoing [22]. The prevalence of treated ESKD in sub-Saharan Africa is lower than that of other developing countries $(<100 \mathrm{pmp})[23,24]$, despite comparable incidence rates, and is likely due to limited access to KRT (only $\sim 10 \%$ of adults with incident ESKD remained on dialysis $\geq 3$ months) [21]. KRT access generally requires selffunding, even in wealthier countries like South Africa, which only provides government funding for KRT if a patient is eligible for transplant [25].

\section{Global Variation in KRT Modality and Practice Patterns}

Although kidney transplantation is the preferred treatment for eligible ESKD patients, dialysis is the predominant therapy in the majority of countries (online suppl. Table 2) [1]. Considerable variation exists in access to and use of kidney transplantation. In 2013, transplantation for ESKD patients ranged from $57-72 \%$ in Nordic countries, Estonia, and the Netherlands to $<10 \%$ in some Asian and eastern European countries [4]. Countries with the highest transplantation rates - mostly Nordic and several other European countries - also have some of the lowest ESKD incidence rates. In such countries, transplantation may be offered to a higher proportion of ESKD patients because of the relatively low number of incident cases. In some countries, by focusing on transplantation or home dialysis, $<1 / 3$ of ESKD patients used in-center HD [4]. These include Hong Kong, Estonia, the Netherlands, New Zealand, and some Nordic countries. This differs from many East and Southeast Asian countries where $\geq 85 \%$ of patients receive in-center HD. Japan is notable because it has a large and mature ESKD program with excellent clinical outcomes, but very low transplantation and home dialysis use. In-center HD is favored over home dialysis partly for historical reasons (dialysis facilities are available and easily accessible, with many placed intentionally near public transportation stops), and kidney donation rates are low, in part due to spiritual beliefs.

Worldwide, HD is the most common dialysis modality [26]. In 2016, in most countries, $\geq 80 \%$ of chronic dialysis patients received in-center HD [1]. Home HD therapy was provided to 9 and $17 \%$ of dialysis patients in Australia and New Zealand, respectively [1]. PD was used by $71 \%$ of dialysis patients in Hong Kong, by $61 \%$ in the Jalisco region of Mexico, and by $57 \%$ in Guatemala [1]. While international differences in dialysis outcomes derive to some extent from variations in patient population, survival differences may also be affected by modifiable variation in dialysis practices, including vascular access, $\mathrm{HD}$ session duration, and dialysis adequacy [4], based on global data reported by the USRDS and observational data from the international prospective cohort study of HD patients in Dialysis Outcomes and Practice Patterns Study (DOPPS) [27].

\section{Vascular Access}

The native arteriovenous fistula (AVF) is widely considered the preferred option of vascular access for most HD patients, providing the best outcomes overall compared with arteriovenous grafts (AVG) or central venous catheters (CVC) [28]. In 2013, Japan and Russia had the highest prevalent use of AVF (>90\%) among 20 participating countries in the DOPPS [29]. AVF use in prevalent HD patients was $49-92 \%$ across these DOPPS countries, while catheter use ranged from 1 to $45 \%$ [29]. In the USA, the Centers for Medicare \& Medicaid Services' (CMS) Fistula First Breakthrough Initiative spurred increased AVF use (24 to 68\%) and decreased AVG (49 to $18 \%$ ) and CVC use (27 to 15\%) from 1997 to 2013 [29]. Large variations in vascular access type also exist in other regions of the world. In South Africa, the prevalence of AVF, AVG, and CVC was 51, 7, and 39\%, respectively, in 2017 [30]. In Argentina, the prevalence of AVF, AVG, and CVC was 
70,15 , and 15\%, respectively, in 2018 [31]. In Vietnam, the prevalence of AVF, AVG, and CVC was $>95,4$, and $1 \%$, respectively, in 2018 [32]. Further, DOPPS data demonstrate substantial international differences in the creation location and successful use of AVFs [33]. Specifically, successful use of newly created AVFs ( $\geq 30$ days of continuous use) was $87 \%$ in Japan, $67 \%$ in Europe/Australia and New Zealand, and 64\% in the USA. Median time until first successful AVF use was 10 days in Japan, 46 days in Europe/Australia and New Zealand, and 82 days in the USA. The factors that may explain these AVF outcomes include differences in patient characteristics, surgical training, dialysis unit staffing, and HD prescription such as dialysis blood flow [34].

\section{Hemodialysis Session Duration}

Although a recent pragmatic trial evaluating the effect of session duration on clinical outcomes was inconclusive [35], multiple observational studies have demonstrated an association between longer treatment time and improved survival among HD patients [36-38]. In many HICs, incenter HD treatment time is $\geq 4 \mathrm{~h}$ thrice weekly, with Australia/New Zealand, Germany, and Sweden having some of the longest treatment times among DOPPS countries [37]. More recent data indicated that $92 \%$ of patients dialyzed in Australia had session lengths from 240 to $300 \mathrm{~min}$ [39]. In contrast, dialysis session length has shortened in the USA (mean $214 \mathrm{~min}$ ) [37] with higher dialysis blood flow and larger dialyzer size versus other DOPPS countries, partly because of greater reliance on small solute (urea) clearances as a measure of dialysis adequacy than other metrics such as volume management and patientreported outcomes [40]. This variation in session length reflects an interplay between clinical practice guidelines, reimbursement measures, HD unit policies, and provider and patient preferences [4]. Dialysis treatment time is similarly short in the Gulf Cooperation Council (GCC) countries (Bahrain, Kuwait, Oman, Qatar, Saudi Arabia, and the United Arab Emirates) based on DOPPS data from 2012 to 2018 , with a mean of $222 \mathrm{~min}$ and $43 \%$ prevalence for low treatment time ( $<240 \mathrm{~min})$ [41].

\section{Dialysis Adequacy}

The 2015 update of the Kidney Disease Outcomes Quality Initiative (KDOQI) Clinical Practice Guideline for Hemodialysis Adequacy recommends a target single pool Kt/V (spKt/V) of 1.4 per HD session for patients treated thrice weekly, with a minimum delivered $\mathrm{spKt} / \mathrm{V}$ of 1.2 [42]. Since 1996, an increase in dialysis dose has been observed with lower proportions of HD patients with $\mathrm{spKt} / \mathrm{V}<1.2$ in DOPPS countries [43]. Recent DOPPS data from 2015 to 2018 showed that $34 \%$ of HD patients from GCC countries had low spKt/V $<1.2$ versus $5-17 \%$ in Canada, Europe, Japan, and the USA [41]. In the USA, Kt/V dose (not dialysis duration) is tied to the CMS' payment policy to dialysis facilities, with $97 \%$ of $\mathrm{HD}$ patients achieving spKt/V $\geq 1.2$ [1]. In Japan, treatments are longer, with lower blood flow rates, thought to better ensure hemodynamic stability and greater middle molecule clearance, despite a greater likelihood of $s p K t / V$ $<1.2$ [4]. Among 5,784 HD patients from Japan DOPPS from 1999 to 2011, spKt/V <1.2 was observed in 26\% of patients and was associated with greater mortality (adjusted hazard ratio per 0.1 lower spKt/V $=1.10$; $95 \% \mathrm{CI}$ : 1.05-1.14) [44]. However, survival in the Japanese HD population overall is considerably better than most other countries, with a crude mortality of $9.8 \%$ in 2013 [45]. Thus, despite this relatively low mortality rate, opportunities remain to improve the dialysis dose in Japan. In LMICs such as India, twice-weekly HD is a common practice, with about one-fourth of patients undergoing dialysis once a week or "as needed" due to financial constraints [46]. In a single-center study of $463 \mathrm{HD}$ patients in Southern India, only $50 \%$ of the treatments delivered a $\mathrm{spKt} / \mathrm{V} \geq 1.0$ [47]. In another single-center study of $50 \mathrm{pa}-$ tients on twice-weekly HD, only $28 \%$ of sessions delivered standardized $\mathrm{Kt} / \mathrm{V} \geq 2.0$ per week (mean 1.4) [48].

\section{Global Variation in Mortality Rates in ESKD}

According to the 2013 Global Burden of Disease Study, age-standardized death rate caused by CKD increased from 11.6 to 15.8 per 100,000 between 1990 and 2013 [49]. In 2013, CKD ranked 19th for global years of life lost, a measure of premature death. Although most ESKD registries report incidence and prevalence data, survival data are preponderantly from HICs (online suppl. Table 1). For patients with ESKD onset from 2004 to 2008, treated with dialysis or transplantation, unadjusted 5-year survival was $41 \%$ in the USA, $48 \%$ in Europe, and $60 \%$ in Japan, despite patients being 2-3 years older on average in Europe and Japan versus the USA and Japan having few transplant patients [4]. Excluding transplant, unadjusted 5-year survival for dialysis was 39\% in the USA, $41 \%$ in Europe, and 60\% in Japan [4]. The European Re- 
nal Association-European Dialysis and Transplant Association (ERA-EDTA) Registry Annual Report 2016 showed that for patients starting dialysis from 2007 to 2011 across European countries, 5-year unadjusted survival was stable at $42 \%$ [50]. DOPPS analyses demonstrate that demographic factors and comorbid diseases accounted for some, but not all, of the differences in dialysis mortality between the USA, Europe, and Japan [51]. Other factors, such as variations in dialysis practice, may contribute to differing survival outcomes.

\section{Mortality in the USA}

In 2016, adjusted mortality rates for ESKD, dialysis, and transplant patients were 134, 164 (166 for HD and 154 for PD patients), and 29 per 1,000 patient-years, respectively [1]. Overall mortality rates among ESKD (dialysis and transplant) patients have declined from 2001 to 2016, with rates leveling during recent years (the adjusted death rate decreased by $29 \%$ over this period). Specifically, reductions in adjusted mortality rates from 2001 to 2016 were $28 \%$ for HD and $43 \%$ for PD patients. The reasons for increased ESKD survival are unknown, but may relate to technical advances in dialysis, new pharmaceutical agents, and improved practice guidelines adherence [52]. Increased access to transplant and improved allograft survival may also be contributory. Nonetheless, absolute mortality rates remain high in ESKD, particularly for maintenance dialysis.

\section{Global and Socioeconomic Disparities in the Burden of ESKD and Access to KRT}

CKD is a global health challenge, especially in LMICs [53]. A majority of people in developing countries have limited incomes and cannot afford health insurance, which risks personal financial crises from out-of-pocket medical costs for both CKD care and KRT [54]. There is a greater prevalence of KRT among groups of people with a higher income level [55], which is consistent with the notion that KRT access is highly dependent on health care expenditures and economic strength of individual countries (online suppl. Table 2) [56]. Most KRT patients (93\%) live in high-income and upper-middle-income countries, with only $7 \%$ living in lower-income countries [2]. The ISN's 2019 GKHA survey showed a treated ESKD prevalence of $966 \mathrm{pmp}$ in high-income, $550.2 \mathrm{pmp}$ in upper-middle, $321 \mathrm{pmp}$ in lower-middle, and $4.4 \mathrm{pmp}$ in low-income countries [3]. Although patients receiving KRT represent a small fraction of the global population $(\sim 0.038 \%)$ [2], they absorb $2-4 \%$ of the health care budget of some countries, creating problems of prioritization and opportunity costs [57]. Dialysis in LMICs is primarily provided in the private sector, and high out-of-pocket expenses often lead to household financial depletion, followed by treatment discontinuation and death once resources are exhausted [58]. In a single-center study of 320 ESKD patients initiated on maintenance HD in Nigeria, $>80 \%$ of the patients funded dialysis treatments from outof-pocket payment [59]. Within 12 weeks of initiation, $98 \%$ had dropped out of the program through deaths and abandonment, and only $2 \%$ were able to fund treatments beyond 12 weeks.

Disparity in access to KRT is not limited to LMICs. Some of the most explicit examples of inequity are evident in undocumented immigrant ESKD care. In the USA, undocumented immigrants with ESKD (currently estimated between 5,500 and 8,857) [60] are ineligible for Medicare, and coverage decisions are made at state or local levels [61]. The 2 main treatment options, emergencyonly hemodialysis (EOHD) and chronic outpatient dialysis, highlight the dilemma between principles of justice and societal standards. Some patients on EOHD are dialyzed once to twice weekly while others just once a month [62]. Not surprisingly, EOHD is associated with psychosocial distress, life-threating physical symptoms, and poor outcomes with a mean dialysis vintage of 16 months at the time of death $[63,64]$. A retrospective cohort study involving 211 undocumented patients in 3 states demonstrated a 14 -fold increase in 5-year relative hazard of mortality for EOHD versus standard chronic outpatient dialysis [65]. Enrollment in private health insurance coverage and subsequent standard thrice weekly dialysis results in improved 1-year mortality and cost savings in undocumented patient care [66]. In 12 states, undocumented immigrants are able to receive chronic outpatient dialysis through Emergency Medicaid coverage [67]. In other states, outpatient dialysis services may be acquired through private insurance (sometimes provided by nonprofit and charitable organizations) or through countyfunded and safety-net hospital-funded outpatient dialysis centers. Thus, ESKD care for this vulnerable population is highly variable between states, leaving many undocumented patients relying on EOHD with resultant poor health outcomes that can only be ameliorated by clinically sound, humane, and economically sensible health policy [68]. 
Table 1. Strategies to reduce global burden of ESKD and inequities in access to KRT

1. Promote a global focus on creating and supporting a culture of health, with an emphasis on primary prevention of CKD

2. Increase awareness of CKD as a public health issue among the population, health care providers, and policymakers

3. Implement effective and affordable early detection, prevention, and treatment programs for CKD

Management of noncommunicable diseases to include hypertension, diabetes, obesity, and cardiovascular disease

Blockade of the renin-angiotensin system

Prevention of AKI and CKD from environmental exposures (nephrotoxic effects from herbal medicines and contaminated water and soil)

Management of communicable diseases to include HIV and waterborne diseases

4. Develop an appropriate national government policy of KRT delivery to promote equity in resource allocation

5. Promote cost-effective home dialysis modality such as PD and develop affordable dialysis techniques (using domestic manufacturing of dialysis consumables to reduce costs, point-of-care dialysate production)

6. Lower barriers for patients to receive kidney transplant since it is the most cost-effective KRT modality and results in the best clinical outcomes (using generic immunosuppressive drugs)

7. Finance prevention and treatment of ESKD with a mix of government, private, and nongovernmental, not-for-profit funding

8. Assess and promote approaches in relation to the local and national levels of economic development and resources through a lens of justice and equity

9. Increase manpower resources (nephrologists, nephrology nurses, dialysis technicians, and general practitioners)

10. Educate and train local community experts in partnership with governments, nongovernmental organizations, and the pharmaceutical industry

11. Implement global evidence-based guidelines and professional standards in the provision of KRT with guidance on ethical issues

ESKD, end-stage kidney disease; KRT, kidney replacement therapy; CKD, chronic kidney disease; PD, peritoneal dialysis; AKI, acute kidney injury; HIV, human immunodeficiency virus.

Significant global inequities also exist for kidney transplantation, which is the most cost-effective treatment for ESKD (particularly beyond the first year after transplant) due to reduced costs and improved survival and quality of life outcomes [69]. Gross domestic product per capita correlates with kidney transplant prevalence and kidney transplant as a proportion of overall KRT population, reflecting greater transplant rates in HIC [55]. Unmet needs for kidney transplantation disproportionately affect LMICs due to a lack of health care infrastructure, costs of transplant surgery and immunosuppressive drugs, infectious disease (e.g., tuberculosis), geographic remoteness, commercial incentives that favor dialysis, lack of a legal framework governing brain death, and religious and cultural beliefs [70]. In a single-center study of subsidized kidney transplantation in a public-sector hospital in India, $82 \%$ patients experienced financial crisis [71]. Greater than $20 \%$ of the transplant recipients sold property as a source of funding for treatment-related expenditure, and a majority did not have identified means to pay for immunosuppressive medications [71].
Strategies to reduce ESKD burden and KRT access inequities at a provider level include early CKD detection, prevention and treatment programs with attention to education and lifestyle intervention, communicable diseases, noncommunicable diseases (hypertension, diabetes, obesity, and cardiovascular disease), and avoidance of nephrotoxic agents (including over-the-counter and nontraditional remedies) [72]. At a community/system level, reductions in environmental toxins (air pollutants, heavy metals, agrichemicals, and contaminated water and soil) [73], improved access to healthy foods, education, and healthy living conditions by ensuring equitable access to housing and employment, health care provider capacity building, health system organization, and government policy grounded in environmental, social, and economic justice are necessary $[55,74,75]$. Table 1 lists strategies to improve KRT access within an ethical framework [76], through consideration of affordability, availability, and acceptability in KRT delivery $[2,77]$. Using these strategies, a country may develop a tailored national management program that could account for resource 
limitations and local needs [54]. International programs such as Kidney Disease Improving Global Outcomes (KDIGO) provide direction on how to adapt HIC-driven guidelines for LMICs [78]. LMICs can leverage support from international organizations (e.g., ISN), industry, and academic medical centers to address workforce capacity through educational ambassador programs, sister kidney centers, fellowships, web-based teaching programs, and telemedicine [79]. Finally, health information systems, such as registries, are essential in permitting accurate problem assessment and guiding resource allocation and policy development [80].

\section{Conclusions}

In this review, we explore the global epidemiology of ESKD and inequities in access to KRT. The incidence rates of treated ESKD have remained relatively stable from 2003 to 2016 in many higher-income countries (Nordic and other European countries, Australia, New Zealand, Japan, and the USA) but have risen substantially, predominantly, in East and Southeast Asian countries. The prevalence of treated ESKD has increased worldwide, likely due to improving ESKD survival, population demographic shifts, higher prevalence of risk factors for ESKD, and increasing KRT access in countries with growing economies. Unadjusted 5-year survival of ESKD patients receiving KRT was $41 \%$ in the USA, $48 \%$ in Europe, and $60 \%$ in Japan. Dialysis is the predominant KRT in the majority of countries, with HD being the most common modality. Variations in dialysis practice patterns account for some of the differences in survival outcomes globally. Worldwide, there is a greater KRT prevalence in higherincome populations, and the number of people who die prematurely because of lack of KRT access is estimated at up to 3 times higher than the number who receive treatment. Greater than $90 \%$ of ESKD patients receiving KRT in the world live in high-income and upper-middle-income countries. This large treatment gap demands a focus on population-based prevention strategies and devel- opment of affordable and cost-effective KRT. Achieving global equity in access to KRT will require concerted efforts in advocating effective public policy, health care delivery, workforce capacity, education, research, and support from the government, private sector, nongovernmental, and professional organizations.

\section{Acknowledgements}

Part of this manuscript was based on the Epidemiology and Outcome of ESKD topic for the updated American Society of Nephrology's online Dialysis Core Curriculum, presented by Dr. Nee and Dr. Yuan.

\section{Conflict of Interest Statement}

The authors declare no conflicts of interests.

\section{Funding Sources}

This research did not receive any funding from agencies in the public, commercial, or not-for-profit sectors. Dr. Yan is supported in part by the National Institutes of Health/National Institute of Diabetes and Digestive and Kidney Diseases grant R01DK112008. Dr. Norris is supported by NIH grants UL1TR000124 and P30AG021684.

\section{Author Contributions}

Concept and design: R.N. and C.M.Y.; manuscript drafting: J.T., M.J., G.Y., K.C.N., C.M.Y., and R.N.; manuscript critical revisions: J.T., K.C.N., L.Y.A., C.M.Y., and R.N. All authors approved the final version for submission.

\section{Disclaimer}

The views expressed in this review article are those of the authors and do not reflect the official policy of the Department of the Army/Navy/Air Force, the Department of Defense, or the US government.

\section{References}

Global Perspectives of ESKD and KRT
1 United States Renal Data System. 2018 USRDS annual data report: epidemiology of kidney disease in the United States. Bethesda, MD: National Institutes of Health, National Institute of Diabetes and Digestive and Kidney Diseases; 2018.

2 Liyanage T, Ninomiya T, Jha V, Neal B, Patrice HM, Okpechi I, et al. Worldwide access to treatment for end-stage kidney disease: a systematic review. Lancet. 2015;385(9981): 1975-82.

3 International Society of Nephrology. Global kidney health atlas. 2nd ed. 2019. Available from: https: //www.theisn.org/initiatives/ global-kidney-health-atlas. Accessed 2020 Nov 17. 
4 Robinson BM, Akizawa T, Jager KJ, Kerr PG, Saran R, Pisoni RL. Factors affecting outcomes in patients reaching end-stage kidney disease worldwide: differences in access to renal replacement therapy, modality use, and haemodialysis practices. Lancet. 2016; 388(10041):294-306.

5 Pippias M, Jager KJ, Kramer A, Leivestad T, Sánchez MB, Caskey FJ, et al. The changing trends and outcomes in renal replacement therapy: data from the ERA-EDTA registry. Nephrol Dial Transplant. 2016;31(5):831-41.

$6 \mathrm{Wu}$ M-Y, Wu M-S. Taiwan renal care system: a learning health-care system. Nephrology. 2018;23(Suppl 4):112-5.

7 Harris DCH, Davies SJ, Finkelstein FO, Jha V, Donner J-A, Abraham G, et al. Increasing access to integrated ESKD care as part of universal health coverage. Kidney Int. 2019;95(4S): S1-33.

8 Wang J, Zhang L, Tang SC, Kashihara N, Kim YS, Togtokh A, et al. Disease burden and challenges of chronic kidney disease in North and East Asia. Kidney Int. 2018;94(1):22-5.

9 McCullough KP, Morgenstern H, Saran R, Herman WH, Robinson BM. Projecting ESRD incidence and prevalence in the United States through 2030. J Am Soc Nephrol. 2019; 30(1):127-35.

10 Nee R, Agodoa LY. Racial differences in kidney disease and end-stage kidney disease in the USA. In: Garcia-Garcia G, Agodoa LY, Norris KC, editors. Chronic kidney disease in disadvantaged populations. 1st ed. San Diego, CA: Academic Press (Elsevier); 2017. p. 6575.

11 Nicholas SB, Kalantar-Zadeh K, Norris KC. Racial disparities in kidney disease outcomes. Semin Nephrol. 2013;33(5):409-15.

12 Marmot M, Friel S, Bell R, Houweling TA, Taylor S; Commission on Social Determinants of Health. Closing the gap in a generation: health equity through action on the social determinants of health. Lancet. 2008; 372(9650):1661-9.

13 Norton JM, Moxey-Mims MM, Eggers PW, Narva AS, Star RA, Kimmel PL, et al. Social determinants of racial disparities in CKD. J Am Soc Nephrol. 2016;27(9):2576-95.

14 Crews DC, Pfaff T, Powe NR. Socioeconomic factors and racial disparities in kidney disease outcomes. Semin Nephrol. 2013;33(5):468-75.

15 Morton RL, Schlackow I, Mihaylova B, Staplin ND, Gray A, Cass A. The impact of social disadvantage in moderate-to-severe chronic kidney disease: an equity-focused systematic review. Nephrol Dial Transplant. 2016;31(1): 46-56.

16 Bello AK, Levin A, Tonelli M, Okpechi IG, Feehally J, Harris D, et al. Assessment of global kidney health care status. JAMA. 2017; 317(18): 1864-81.

17 Wang F, Yang C, Long J, Zhao X, Tang W, Zhang D, et al. Executive summary for the 2015 annual data report of the China kidney disease network (CK-NET). Kidney Int. 2019; 95(3):501-5.
18 Varughese S, Abraham G. Chronic kidney disease in India: a clarion call for change. Clin J Am Soc Nephrol. 2018;13(5):802-4.

19 Modi GK, Jha V. The incidence of end-stage renal disease in India: a population-based study. Kidney Int. 2006;70(12):2131-3.

20 Rajapurkar MM, John GT, Kirpalani AL, Abraham G, Agarwal SK, Almeida AF, et al. What do we know about chronic kidney disease in India: first report of the Indian CKD registry. BMC Nephrol. 2012;13:10.

21 Ashuntantang G, Osafo C, Olowu WA, Arogundade F, Niang A, Porter J, et al. Outcomes in adults and children with end-stage kidney disease requiring dialysis in sub-Saharan Africa: a systematic review. Lancet Glob Health. 2017;5(4):e408-17.

22 Davids MR, Eastwood JB, Selwood NH, Arogundade FA, Ashuntantang G, Gharbi MB, et al. A renal registry for Africa: first steps. Clin Kidney J. 2016;9(1):162-7.

23 Grassmann A, Gioberge S, Moeller S, Brown G. ESRD patients in 2004: global overview of patient numbers, treatment modalities and associated trends. Nephrol Dial Transplant. 2005;20(12):2587-93.

24 Barsoum RS. Chronic kidney disease in the developing world. N Engl J Med. 2006; 354(10):997-9.

25 Naicker S. End-stage renal disease in sub-Saharan and South Africa. Kidney Int Suppl. 2003;(83):S119-22.

26 Himmelfarb J, Vanholder R, Mehrotra R, Tonelli M. The current and future landscape of dialysis. Nat Rev Nephrol. 2020;16(10): $573-85$.

27 Port FK, Morgenstern H, Bieber BA, Karaboyas A, McCullough KP, Tentori F, et al. Understanding associations of hemodialysis practices with clinical and patient-reported outcomes: examples from the DOPPS. Nephrol Dial Transplant. 2017;32(Suppl_2): iil06-12.

28 Vascular Access Work Group. Clinical practice guidelines for vascular access. Am J Kidney Dis. 2006;48(Suppl 1):S248-73.

29 Pisoni RL, Zepel L, Port FK, Robinson BM. Trends in US vascular access use, patient preferences, and related practices: an update from the US DOPPS practice monitor with international comparisons. Am J Kidney Dis. 2015; 65(6):905-15

30 Jardine T, Davids MR. Global dialysis perspective: South Africa. Kidney360. 2020; 1(12):1432-6

31 Orias M, Rosa Diez GJ. Global dialysis perspective: Argentina. Kidney360. 2020;1(7): 676-9.

32 Van BP, Duc CV. Global dialysis perspective: Vietnam. Kidney360. 2020;1:974-6.

33 Pisoni RL, Zepel L, Fluck R, Lok CE, Kawanishi $H$, Süleymanlar G, et al. International differences in the location and use of arteriovenous accesses created for hemodialysis: results from the Dialysis Outcomes and Practice Patterns Study (DOPPS). Am J Kidney Dis. 2018;71(4):469-78.
34 Allon M. Lessons from international differences in vascular access practices and outcomes. Am J Kidney Dis. 2018;71(4):452-4.

35 Dember LM, Lacson E Jr, Brunelli SM, Hsu JY, Cheung AK, Daugirdas JT, et al. The TiME trial: a fully embedded, cluster-randomized, pragmatic trial of hemodialysis session duration. J Am Soc Nephrol. 2019;30(5):890-903.

36 Brunelli SM, Chertow GM, Ankers ED, Lowrie EG, Thadhani R. Shorter dialysis times are associated with higher mortality among incident hemodialysis patients. Kidney Int. 2010; 77(7):630-6.

37 Tentori F, Zhang J, Li Y, Karaboyas A, Kerr P, Saran R, et al. Longer dialysis session length is associated with better intermediate outcomes and survival among patients on in-center three times per week hemodialysis: results from the Dialysis Outcomes and Practice Patterns Study (DOPPS). Nephrol Dial Transplant. 2012;27(11):4180-8.

38 Saran R, Bragg-Gresham JL, Levin NW, Twardowski ZJ, Wizemann V, Saito A, et al. Longer treatment time and slower ultrafiltration in hemodialysis: associations with reduced mortality in the DOPPS. Kidney Int. 2006;69(7):1222-8.

39 Damasiewicz MJ, Polkinghorne KR. Global dialysis perspective: Australia. Kidney360. 2020;1(1):48-51.

40 Perl J, Dember LM, Bargman JM, Browne T, Charytan DM, Flythe JE, et al. The use of a multidimensional measure of dialysis adequacy-moving beyond small solute kinetics. Clin J Am Soc Nephrol. 2017;12(5):839-47.

41 AlSahow A, Muenz D, Al-Ghonaim MA, Al Salmi I, Hassan M, Al Aradi AH, et al. Kt/V: achievement, predictors and relationship to mortality in hemodialysis patients in the Gulf Cooperation Council countries: results from DOPPS (2012-18). Clin Kidney J. 2020.

42 National Kidney Foundation. KDOQI clinical practice guideline for hemodialysis adequacy: 2015 update. Am J Kidney Dis. 2015; 66(5):884-930.

43 Port FK, Pisoni RL, Bommer J, Locatelli F, Jadoul M, Eknoyan G, et al. Improving outcomes for dialysis patients in the international Dialysis Outcomes and Practice Patterns Study. Clin J Am Soc Nephrol. 2006;1(2):24655.

44 Kimata N, Karaboyas A, Bieber BA, Pisoni RL, Morgenstern H, Gillespie BW, et al. Gender, low Kt/V, and mortality in Japanese hemodialysis patients: opportunities for improvement through modifiable practices. $\mathrm{He}$ modial Int. 2014;18(3):596-606.

45 Masakane I, Nakai S, Ogata S, Kimata N, Hanafusa N, Hamano T, et al. An overview of regular dialysis treatment in Japan (as of 31 December 2013). Ther Apher Dial. 2015; 19(6):540-74.

46 Bharati J, Jha V. Global dialysis perspective: India. Kidney360. 2020;1:1143-7.

Thurlow/Joshi/Yan/Norris/Agodoa/ Yuan/Nee 
47 Rao M, Juneja R, Shirly RB, Jacob CK. Haemodialysis for end-stage renal disease in Southern India: a perspective from a tertiary referral care centre. Nephrol Dial Transplant. 1998;13(10):2494-500.

48 Chauhan R, Mendonca S. Adequacy of twice weekly hemodialysis in end stage renal disease patients at a tertiary care dialysis centre. Indian J Nephrol. 2015;25(6):329-33.

49 GBD 2013 Mortality and Causes of Death Collaborators. Global, regional, and national age-sex specific all-cause and cause-specific mortality for 240 causes of death, 1990-2013: a systematic analysis for the Global Burden of Disease Study 2013. Lancet. 2015;385(9963): $117-71$.

50 Kramer A, Pippias M, Noordzij M, Stel VS, Andrusev AM, Aparicio-Madre MI, et al. The European Renal Association-European Dialysis and Transplant Association (ERA-EDTA) registry annual report 2016: a summary. Clin Kidney J. 2019;12(5):702-20.

51 Goodkin DA, Bragg-Gresham JL, Koenig KG, Wolfe RA, Akiba T, Andreucci VE, et al. Association of comorbid conditions and mortality in hemodialysis patients in Europe, Japan, and the United States: the Dialysis Outcomes and Practice Patterns Study (DOPPS). J Am Soc Nephrol. 2003;14(12):3270-7.

52 Foster BJ, Mitsnefes MM, Dahhou M, Zhang $\mathrm{X}$, Laskin BL. Changes in excess mortality from end stage renal disease in the United States from 1995 to 2013. Clin J Am Soc Nephrol. 2018;13(1):91-9.

53 Crews DC, Bello AK, Saadi G; World Kidney Day Steering Committee. Burden, access, and disparities in kidney disease. Kidney Int. 2019;95(2):242-8.

54 Jha V, Garcia-Garcia G, Iseki K, Li Z, Naicker S, Plattner B, et al. Chronic kidney disease: global dimension and perspectives. Lancet. 2013;382(9888):260-72.

55 White SL, Chadban SJ, Jan S, Chapman JR, Cass A. How can we achieve global equity in provision of renal replacement therapy? Bull World Health Organ. 2008;86(3):229-37.

56 Garcia-Garcia G, Jha V; World Kidney Day Steering Committee. CKD in disadvantaged populations. Kidney Int. 2015 Feb;87(2):2513.

57 Vanholder R, Annemans L, Brown E, Gansevoort R, Gout-Zwart JJ, Lameire N, et al. Reducing the costs of chronic kidney disease while delivering quality health care: a call to action. Nat Rev Nephrol. 2017;13(7):393409.

58 Luyckx VA, Miljeteig I, Ejigu AM, Moosa MR. Ethical challenges in the provision of dialysis in resource-constrained environments. Semin Nephrol. 2017;37(3):273-86.
59 Alasia DD, Emem-Chioma P, Wokoma FS. A single-center 7-year experience with endstage renal disease care in Nigeria-a surrogate for the poor state of ESRD care in Nigeria and other sub-saharan african countries: advocacy for a global fund for ESRD care program in sub-saharan african countries. Int J Nephrol. 2012;2012:639653.

60 Rodriguez R, Cervantes L, Raghavan R. Estimating the prevalence of undocumented immigrants with end-stage renal disease in the United States. Clin Nephrol. 2020;93(1):10812.

61 Rodriguez RA. Dialysis for undocumented immigrants in the United States. Adv Chronic Kidney Dis. 2015;22(1):60-5.

62 Raghavan R. When access to chronic dialysis is limited: one center's approach to emergent hemodialysis. Semin Dial. 2012;25(3):26771.

63 Cervantes L, Fischer S, Berlinger N, Zabalaga M, Camacho C, Linas S, et al. The illness experience of undocumented immigrants with end-stage renal disease. JAMA Intern Med. 2017;177(4):529-35.

64 Cervantes L, O'Hare A, Chonchol M, Hull M, Van Bockern J, Thompson M, et al. Circumstances of death among undocumented immigrants who rely on emergency-only hemodialysis. Clin J Am Soc Nephrol. 2018;13(9): 1405-6.

65 Cervantes L, Tuot D, Raghavan R, Linas S, Zoucha J, Sweeney L, et al. Association of emergency-only vs. standard hemodialysis with mortality and health care use among undocumented immigrants with end-stage renal disease. JAMA Intern Med. 2018;178(2):18895.

66 Nguyen OK, Vazquez MA, Charles L, Berger JR, Quiñones H, Fuquay R, et al. Association of scheduled vs. emergency-only dialysis with health outcomes and costs in undocumented immigrants with end-stage renal dDsease. JAMA Intern Med. 2019;179(2):175-83.

67 Rizzolo K, Novick TK, Cervantes L. Dialysis care for undocumented immigrants with kidney failure in the COVID-19 Era: public health implications and policy recommendations. Am J Kidney Dis. 2020;76(2):255-7.

68 Cervantes L, Mundo W, Powe NR. The status of provision of standard outpatient dialysis for US undocumented immigrants with ESKD. Clin J Am Soc Nephrol. 2019;14(8): 1258-60.

69 Muralidharan A, White S. The need for kidney transplantation in low- and middle-income countries in 2012: an epidemiological perspective. Transplantation. 2015;99(3): $476-81$.
70 Garcia GG, Harden PN, Chapman JR; World Kidney Day Steering Committee 2012. World Kidney Day 2012: the global role of kidney transplantation. Am J Kidney Dis. 2012;59(3): 319-24.

71 Ramachandran R, Jha V. Kidney transplantation is associated with catastrophic out of pocket expenditure in India. PLoS One. 2013; 8(7):e67812.

72 Luyckx VA, Tuttle KR, Garcia-Garcia G, Gharbi MB, Heerspink HJL, Johnson DW, et al. Reducing major risk factors for chronic kidney disease. Kidney Int Suppl. 2017;7(2): 71-87.

73 Scammell MK, Sennett CM, Petropoulos ZE, Kamal J, Kaufman JS. Environmental and occupational exposures in kidney disease. Semin Nephrol. 2019;39(3):230-43.

74 Levin A, Tonelli M, Bonventre J, Coresh J, Donner J-A, Fogo AB, et al. Global kidney health 2017 and beyond: a roadmap for closing gaps in care, research, and policy. Lancet. 2017;390(10105):1888-917.

75 Moosa MR, Norris KC. Sustainable social development: tackling poverty to achieve kidney health equity. Nat Rev Nephrol. 2021;17(1): 3-4.

76 Luyckx VA, Martin DE, Moosa MR, Bello AK, Bellorin-Font E, Chan TM, et al. Developing the ethical framework of end-stage kidney disease care: from practice to policy. Kidney Int Suppl. 2020;10(1):e72-7.

77 Van Biesen W, Jha V, Abu-Alfa AK, Andreoli SP, Ashuntantang G, Bernieh B, et al. Considerations on equity in management of endstage kidney disease in low- and middle-income countries. Kidney Int Suppl. 2020; 10(1):e63-71.

78 Jha V, Arici M, Collins AJ, Garcia-Garcia G Hemmelgarn BR, Jafar TH, et al. Understanding kidney care needs and implementation strategies in low- and middle-income countries: conclusions from a "Kidney Disease: Improving Global Outcomes" (KDIGO) controversies conference. Kidney Int. 2016;90(6): 1164-74.

79 Swanepoel CR, McCulloch MI, Abraham G, Donner JA, Alrukhaimi MN, Blake PG, et al. Challenges for sustainable end-stage kidney disease care in low-middle-income countries: the problem of the workforce. Kidney Int Suppl. 2020;10(1):e49-54.

80 Pecoits-Filho R, Okpechi IG, Donner JA, Harris DCH, Aljubori HM, Bello AK, et al. Capturing and monitoring global differences in untreated and treated end-stage kidney disease, kidney replacement therapy modality, and outcomes. Kidney Int Suppl. 2020;10(1): e3-9. 